\title{
Independent Assessment of the Quality of Education in Russia: Results and Development Directions
}

\author{
Yulia Fedorchuk ${ }^{1, a}$, Sergey Neustroyev ${ }^{1, b}$, Anna Arinushkina ${ }^{1, c^{*}}$ \\ 1 Institute of Education Management of the Russian Academy of Education, 105062, 16 \\ Zhukovskogo str., Moscow, Russia

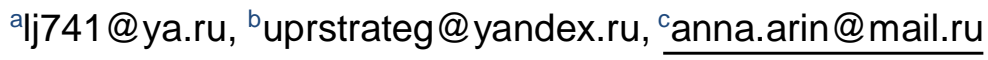 \\ ${ }^{*}$ Corresponding author
}

Keywords: quality of education, independent assessment of quality, consumers of educational services, informational transparency of education, development of education, multi-level quality assessment systems

\begin{abstract}
The article considers certain elements of the world and national system of independent assessment of the education quality. The structure of the system at the federal, regional, and local levels, the regulatory framework, and the results are considered. The paper also analyzes the normative changes in the course change on the assessment of the system of conditions for the provision of educational services, their causes, and directions of development.
\end{abstract}

\section{Introduction}

The international system for assessing the quality of education is implemented through two directions. First, an assessment is made within the education system from international studies to the class level; its results are used primarily for the development of the system itself. Second, an assessment is made outside the education system, is carried out by actors being independent with respect to the current education system, and the results are used in the interests of consumers. The second direction is developing in all countries, including Russia, since the evaluation function must belong to an independent actor; otherwise, the meaning of an objective evaluation is lost. In order to make right management decisions, these assessments must be relevant.

\section{Methodology}

The article examines an independent system for assessing the quality of education, assessing the quality of conditions for providing services by educational organizations, identifies indicators and results. The perception of educational services, along with other services, is an integral component of the individual's assessment of the quality parameters of their own living environment, influences social well-being, social optimism of the population, and attitudes to social institutions of modern society. Evaluation of qualitative characteristics of these services is carried out through the procedure of expression by an individual of a certain degree of subjective satisfaction as a result of their consumption.

"Satisfaction with a service" is a subjective assessment by a consumer of the degree to which a service provider realizes his needs and expectations. Since the market has information asymmetry, the choice of provider of educational services is largely random. To compensate for the lack of awareness of potential consumers, public ratings are allowed as a result of an independent assessment. However, a public rating is not only a tool for informing consumers, but also an effective feedback mechanism for social service providers and their beneficiaries. Evaluation of the quality of services provided is not only important for consumer choice, it is the basis of the expectations of potential consumers. Therefore, when building public ratings, it is necessary to identify the most significant aspects of the quality of services of social organizations based on a limited range of indicators, which would be simple and understandable to consumers.

\section{Research}

Providing reliable and relevant information to managers and employees of an education system as well as 
consumers of educational services through the formation of an all-Russian system for assessing the quality of education is defined as the goal of the subprogramme 3 "Development of the system for assessing the quality of education and informational transparency of the education system" of the Russian State Program "Education Development for 2013 -2020," approved by the Government of the Russian Federation on April 15, 2014 No. 295 [1]. The inclusion of consumers of educational services in the evaluation of the education system through the development of mechanisms for independent assessment of the quality of education is one of the key strategic objectives of the development of the education system at the level of regions, municipalities, and individual organizations. The formation of the demanded system for assessing the quality of education and educational results is determined by one of the objectives of the Federal Target Program for the Development of Education for 2016-2020 [2]. The multi-level system for assessing the quality of education in Russia includes the following elements by object of assessment:

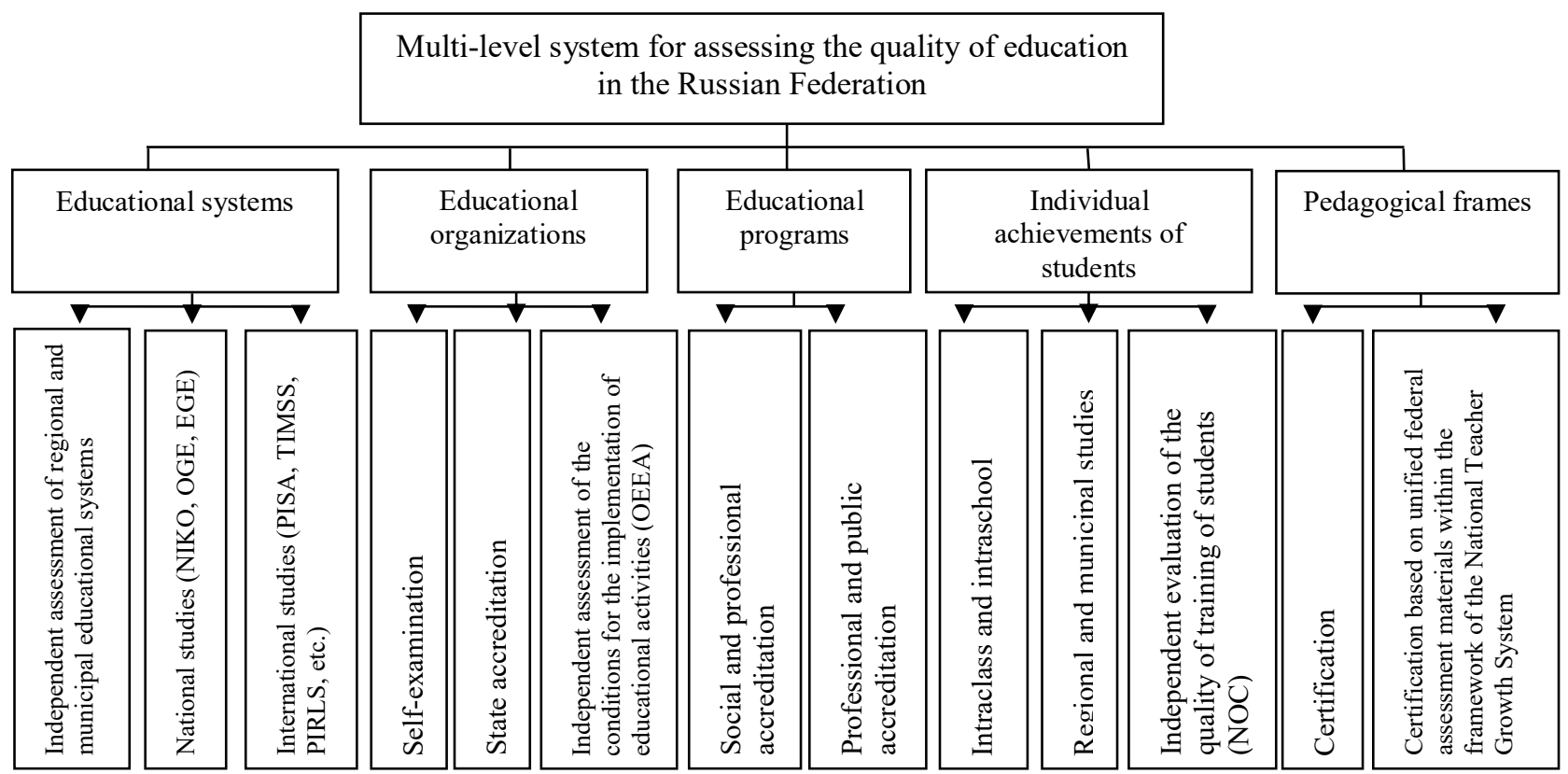

Fig. 1. A multi-level system for assessing the quality of education in the Russian Federation by objects of assessment.

In this study, one of the assessment blocks is be considered, which is an independent assessment of the quality of the conditions for the implementation of educational activities by educational organizations.

In the Russian Federation, as a separate concept, "independent assessment of the quality of services" appears in 2005 is made out conceptually in 2009. Work on the creation of an independent evaluation system began in 2012 as part of the execution of the Presidential Decree of 07/05/2012 N 597 "On measures to implement the state social policy" [3]. In paragraph 1, the Government of the Russian Federation was instructed to ensure the formation of an independent system for assessing the quality of work of organizations providing social services, including the definition of performance criteria for these organizations and the introduction of public ratings of their activities.

As a result, the basic document regulating this procedure was adopted - Resolution of the Government of the Russian Federation of 30.03.2013 No 286 [4]. In addition, federal sectoral ministries developed recommendations for the organization of independent evaluation being addressed to the founders of institutions.

The next step in the formation of an independent evaluation was the adoption in 2013 of the Federal Law No 256-FZ, which established the duty of applying this mechanism at the level of basic sectoral laws, including in education. However, it could not acquire its complete form until the end of 2014, after the introduction and entry into force of changes in the basic sectoral laws, including the Federal Law of 29.12.2012 No 273-FZ "On Education in the Russian Federation" [5]. The introduction of an independent evaluation system and its significance for the social sector have been discussed in many program documents. In particular, the President of the Russian Federation in his Address to the Federal Assembly on 12.04.2014 indicated the need to launch this mechanism and disclose information on the work of institutions [6]. The 
Government of the Russian Federation announced the introduction of public ratings, the identification and dissemination of best practices of social organizations [7]. In this context, the formation of the demanded assessment system has become a target for the education sector [8]. Especially since the rules for conducting an independent assessment are now enshrined at the level of the basic Federal Law No. 273 of Art. 95-95.2 "On education in the Russian Federation."

The methodology for analyzing the official website and other open information sources about the organization, as well as a sample questionnaire for a sociological study, were presented in the guidelines of the Ministry of Education and Science of the Russian Federation and Rosobrnadzor and were the same for the whole of Russia. But each region and municipalities could complement this methodology and offer their own ways of processing the results and their interpretation.

The field of education turned out to be the only industry where independent assessment should be carried out in two forms. One of them, the assessment of the quality of educational activities, is governed by Art. 95.2 of the Law on Education and coincides with the procedures used in relation to institutions of culture, health, and social services. Here the service component of the service is analyzed directly (conditions of its provision). The second type of independent assessment, aimed at studying the quality of training of students (Article 95.1 of the Law on Education), does not apply in other industries. In fact, the professional component of the service is monitored here, i.e. the level of students' mastery of the educational program or its parts.

However, neither in the first nor in the second case, results of an independent assessment do not entail the suspension or revocation of a license to conduct educational activities, suspension or deprivation of state accreditation. This is indicated in paragraph 6 of Art. 95 of the Law on Education.

The relevance of the system of independent assessment of the quality of conditions for the implementation of educational activities by organizations engaged in educational activities (OEEA) is determined by the focus on achieving an educational system of maximum openness for educational users in order to promptly respond to external requests, jointly achieve the efficiency of the system, and meet the individual needs of society and the state.

The organizations engaged in educational activities (OEEA) are carried out in order to provide participants of educational relations with information about the level of organization in the work on the implementation of educational programs based on publicly available information.

In accordance with Article 95 of the Federal Law 273 "On Education in the Russian Federation", an independent assessment of the quality of education (IAQE) includes two areas:

1) independent assessment of the quality of training of students (IAQE);

2) independent assessment of the quality of the conditions for the implementation of educational activities by organizations engaged in educational activities (OEEA).

An independent assessment of the quality of education is carried out by legal entities that carry out specific types of such an assessment (hereinafter, organizations carrying out an independent assessment of the quality of education).

Organizations carrying out an independent assessment of the quality of education post on the Internet information about the procedure and results of an independent assessment of the quality of education and, if necessary, send it to the federal government bodies and executive authorities that carry out government education, local governments. This information about results of an independent assessment of the quality of education is subject to mandatory review by these authorities and is to be taken into account by them when developing measures to improve educational activities and performance assessment of the heads of organizations engaged in educational activities. Results of an independent assessment of the quality of education do not entail the suspension or revocation of a license to conduct educational activities, or the suspension of state accreditation or the deprivation of state accreditation with respect to organizations conducting educational activities.

Based on the results of an independent assessment of the quality of education, ratings of organizations conducting educational activities and (or) educational programs implemented by them can be formed. 
In order to create conditions for the conduct of OEEA, Public Chambers of different levels (federal, regional, and local) form Public Councils for the conduct of OEEA, which now cannot include representatives of government bodies and local authorities, representatives of public associations operating in the field education, managers and employees of educational organizations. The public councils determine the lists of organizations (one organization to be reviewed every three years) and carry out an independent assessment of the quality of conditions for the implementation of educational activities by organizations, taking into account information provided by the operator. In essence, public councils are becoming a central element of the system for assessing the quality of educational activities: they are the ones who perform the main actions in relation to the institutions studied.

OEEA is conducted according to such general criteria as:

- openness and availability of information about organizations engaged in educational activities;

- conditions in which educational activities are carried out (comfort);

- goodwill, politeness of employees;

- satisfaction with conditions for conducting educational activities of organizations and accessibility of services for people with disabilities.

The indicators characterizing the general criteria of the OEEA are set by the federal executive body that performs the functions of formulating state policy and legal regulation in the field of education, with a preliminary discussion at the public council for an independent assessment of quality. Information about the results of OEEA is available on the official websites of state and municipal institutions bus.gov.ru, websites of educational organizations and authorities. The results of OEEA are taken into account when evaluating the effectiveness of managers of educational systems at all levels.

The main principles of the OEEA procedure are:

- regularity and transparency of the assessment procedure;

- assessment is not an end in itself; its results are a guarantee to society that an educational organization meets modern standards in all respects and that this educational institution or a specific educational program has properly formulated goals and conditions for their achievement;

- assessment is done in order to increase information openness and efficiency in the interests of all consumer groups;

- completeness of coverage, reliability and verifiability of indicators obtained from open sources of information;

- stimulation of the continuous development of educational organizations and improvement of educational programs through constant self-examination and planning procedures;

- actions in the interests of participants (including potential ones) of the educational process that are not institutionalized;

- uniform methodology for evaluating and interpreting results to all analyzed organizations.

\section{Conclusion}

Thus, we can note the general concept of the OEEA system: "New challenges to educational systems are the new conditions for the development of assessment systems". Trends in the assessment, both in Russia and in world practice, include the course towards applied solutions, process automation, striving for independent operators, and the development of self-examination procedures. As an independent assessment of education quality of the previous period shows, first, the procedure has a powerful effect on eliminating deficiencies. The identified problems against the background of the activities of similar organizations are promptly corrected. The level and conditions of the services provided are becoming higher and better, closee to world modern standards. The voice of any citizen can be heard, and his opinion can be taken into account, and this is not a mythical "complaint book", but an operational method of reacting to feedback from the consumer. Services can be provided in different conditions, with different quality. Therefore, the translation of 
qualitative assessments of satisfaction or dissatisfaction with services into quantitative standardized parameters will allow making effective decisions to all participants of educational relations. The results of an independent evaluation are also important for management bodies, since they can be used to objectively evaluate the performance of subordinate organizations.

\section{Acknowledgment}

The article was prepared within the framework of the implementation of the State task of the Ministry of Education and Science of Russia for 2018 on the topic No. 27.9385.2017/БЧ "Theoretical and methodological basis of the professional development of education system managers".

\section{References}

[1] Government of Russia. (2014). Resolution of the Government of the Russian Federation of April 15, 2014 № 295. Moscow, Russia.

[2] Government of Russia. (2015). Resolution of the Government of the Russian Federation of 05.23.2015 No. 497 "On the Federal Target Program for the Development of Education for 2016-2020." Retrieved from http://www.consultant.ru/document/cons_doc_LAW_180188.

[3] President of Russia. (2012). Presidential Decree of 05.07.2012 N 597 "On measures to implement state social policy." Moscow, Russia.

[4] Government of Russia. (2013). Resolution of the Government of the Russian Federation of 03.30.2013 No 286. Moscow, Russia.

[5] Garant Database. (2014). Federal Law of July 21, 2014 N 256-FZ "On amendments to certain legislative acts of the Russian Federation on the independent assessment of the quality of service provided by organizations in the sphere of culture, social service, health care and education." Moscow, Russia.

[6] President of Russia. (2014). Message from the President of the Russian Federation to the Federal Assembly on April 12, 2014. Retrieved from http://www. consultant. ru/document/cons_doc_LAW_171774.

[7] Government of Russia. (2015). Section III: The main activities of the Government of the Russian Federation for the period until 2018 (new edition), approved by Government of the Russian Federation on May 14, 2015. Moscow, Russia.

[8] Government of Russia. (2015). Federal target program for the development of education for 20162020, approved by the Decree of the Government of the Russian Federation of 05/23/2015 No 497. Moscow, Russia.

[9] Retrieved from http://www.garant.ru/products/ipo/prime/doc/56654056/

[10] Retrieved from https://www.garant.ru/products/ipo/prime/doc/56648803/ 